\title{
A Nanomedicine Transports a Peptide Caspase-3 Inhibitor across the Blood-Brain Barrier and Provides Neuroprotection
}

\author{
Hulya Karatas, ${ }^{1}$ Yesim Aktas, ${ }^{2}$ Yasemin Gursoy-Ozdemir, ${ }^{1}$ Ebru Bodur, ${ }^{3}$ Muge Yemisci, ${ }^{1}$ Secil Caban, ${ }^{2}$ Atay Vural, ${ }^{1}$ \\ Onur Pinarbasli, ${ }^{2}$ Yilmaz Capan, ${ }^{2}$ Eduardo Fernandez-Megia, ${ }^{4}$ Ramon Novoa-Carballal, ${ }^{4}$ Ricardo Riguera, ${ }^{4}$ \\ Karine Andrieux, ${ }^{5}$ Patrick Couvreur, ${ }^{5}$ and Turgay Dalkara ${ }^{1}$ \\ ${ }^{1}$ Department of Neurology, Faculty of Medicine and Institute of Neurological Sciences and Psychiatry, ${ }^{2}$ Department of Pharmaceutical Technology, Faculty \\ of Pharmacy, and ${ }^{3}$ Department of Biochemistry, Faculty of Medicine, Hacettepe University, 06100 Ankara, Turkey, ${ }^{4}$ Departamento de Química Orgánica, \\ Facultad de Química, and Unidad de Resonancia Magnética Nuclear de Biomoléculas Asociada al Consejo Superior de Investigaciones Científicas, \\ Universidad de Santiago de Compostela, 15782 Santiago de Compostela, Spain, and 5 Physico-Chimie, Pharmacotechnie, Biopharmacie, Faculté de \\ Pharmacie, Université Paris Sud, UMR Centre National de la Recherche Scientifique 8612, 92296 Chatenay Malabry, France
}

Caspases play an important role as mediators of cell death in acute and chronic neurological disorders. Although peptide inhibitors of caspases provide neuroprotection, they have to be administered intracerebroventricularly because they cannot cross the blood-brain barrier (BBB). Herein, we present a nanocarrier system that can transfer chitosan nanospheres loaded with $N$-benzyloxycarbonyl$\mathrm{Asp}(\mathrm{OMe})-\mathrm{Glu}(\mathrm{OMe})$-Val-Asp(OMe)-fluoromethyl ketone (Z-DEVD-FMK), a relatively specific caspase-3 inhibitor, across BBB. Caspase-3 was chosen as a pharmacological target because of its central role in cell death. Polyethylene glycol-coated nanospheres were conjugated to an anti-mouse transferrin receptor monoclonal antibody (TfRMAb) that selectively recognizes the TfR type 1 on the cerebral vasculature. We demonstrate with intravital microscopy that this nanomedicine is rapidly transported across the BBB without being measurably taken up by liver and spleen. Pre- or post-treatment $(2 \mathrm{~h})$ with intravenously injected Z-DEVD-FMK-loaded nanospheres dose dependently decreased the infarct volume, neurological deficit, and ischemia-induced caspase- 3 activity in mice subjected to $2 \mathrm{~h}$ of MCA occlusion and $24 \mathrm{~h}$ of reperfusion, suggesting that they released an amount of peptide sufficient to inhibit caspase activity. Similarly, nanospheres inhibited physiological caspase-3 activity during development in the neonatal mouse cerebellum on postnatal day 17 after closure of the BBB. Neither nanospheres functionalized with TfRMAb but not loaded with Z-DEVD-FMK nor nanospheres lacking TfRMAb but loaded with Z-DEVD-FMK had any effect on either paradigm, suggesting that inhibition of caspase activity and subsequent neuroprotection were due to efficient penetration of the peptide into brain. Thus, chitosan nanospheres open new and exciting opportunities for brain delivery of biologically active peptides that are useful for the treatment of CNS disorders.

\section{Introduction}

Focal or global cerebral ischemia activates caspase-3 by inducing cleavage of its proform in ischemic neurons (Asahi et al., 1997; Chen et al., 1998; Namura et al., 1998). The regional distribution of cleaved caspase- 3 corresponds to the area destined to infarct. It has been reported that caspase- 3 inhibitors increased cell survival after ischemia, which strongly supports a cell death effector role for caspase-3 in ischemic brain injury (Hara et al., 1997; Chen et al., 1998; Ma et al., 2001). Similarly, knocking out the caspase-3 gene is associated with resistance to brain ischemia (Schielke et

\footnotetext{
Received Aug. 27, 2009; accepted Sept. 10, 2009.

T.D.'s work is supported by the Turkish Academy of Sciences. We thank our technician, Mesut Firat, for his valuable help.

Correspondence should be addressed to Dr. Turgay Dalkara, Department of Neurology, Faculty of Medicine and Institute of Neurological Sciences and Psychiatry, Hacettepe University, 06100 Ankara, Turkey. E-mail: tdalkara@hacettepe.edu.tr.

Y. Aktas' present address: Department of Pharmaceutical Technology, Faculty of Pharmacy, Ataturk University, 25240 Erzurum, Turkey.

D0I:10.1523/JNEUROSCI.4246-09.2009

Copyright $\odot 2009$ Society for Neuroscience ～0270-6474/09/2913761-09\$15.00/0
}

al., 1998). Hence, the inhibition of caspase-3-like protease activity is of great interest and may have therapeutic significance for the treatment of cerebral ischemia as well as for several other neurological disorders in which caspase-mediated cell death plays an important pathophysiological role (Chen et al., 1998; Thornberry and Lazebnik, 1998; Schulz et al., 1999).

The peptide $N$-benzyloxycarbonyl-Asp(OMe)-Glu(OMe)Val-Asp(OMe)-fluoromethyl ketone (Z-DEVD-FMK) is a relatively specific and irreversible caspase- 3 inhibitor, and it reduces susceptibility to neuronal cell death (Hara et al., 1997; Thornberry and Lazebnik, 1998; Schulz et al., 1999; Ma et al., 2001). Although this molecule is unable to cross the blood-brain barrier (BBB), Hara et al. demonstrated that Z-DEVD-FMK can reduce both infarct size and behavioral deficits when given intracerebroventricularly (Hara et al., 1997). Therefore, the development of an effective delivery system is needed to provide sufficient peptide concentration in the brain to prevent cell death.

We previously reported that brain delivery of Z-DEVD-FMK could be feasible by way of nanospheres directed to the trans- 


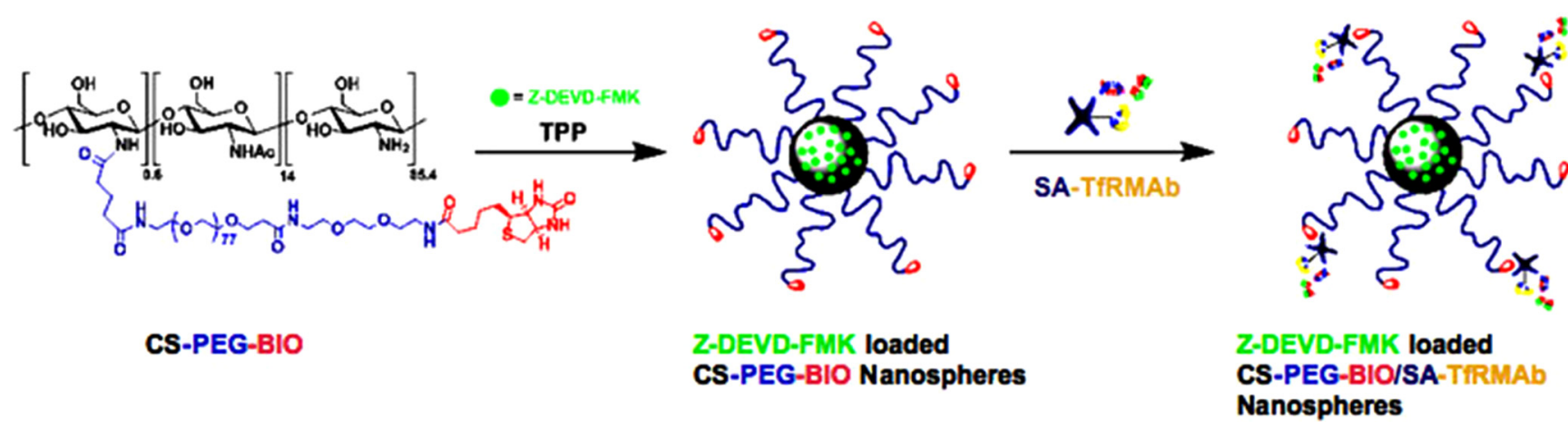

Figure 1. Schematic view of nanospheres. Caspase-3 inhibitor Z-DEVD-FMK is loaded into CS-PEG-BIO nanospheres by an ionic gelation procedure with TPP. The resulting nanospheres are decorated with anti-mouse transferrin antibody by means of biotin-streptavidin technology.

ferrin receptor (TfR) in the mouse (Aktaş et al., 2005). The transferrin receptor type 1 is highly concentrated on the brain capillary endothelium, and it may trigger receptor-mediated transport across the BBB via transcytosis (Jefferies et al., 1984; Pardridge et al., 1991). On systematic administration to mice, polyethylene glycol (PEG)-overcoated chitosan (CS) nanospheres conjugated with an anti-mouse TfR monoclonal antibody (TfRMAb) were localized to the brain parenchyma outside the vascular compartment, whereas the unconjugated nanospheres could not penetrate into the brain (Aktaş et al., 2005). This demonstrated that these novel nanospheres were promising carriers for the transport of the anti-caspase peptide Z-DEVD-FMK into the brain. The nanocarrier system we used in the present study was also made up of PEG-overcoated CS nanospheres conjugated with monoclonal anti-mouse TfR antibody via biotin (BIO)-streptavidin (SA) noncovalent binding. These nanospheres take advantage of the ability of cationic CS to interact with negative charges on the brain endothelium along with the affinity of TfRMAb for the transferrin receptor to trigger receptor-mediated transport across the BBB (Fig. 1). Moreover, the TfRMAb used (R17217) provides selective targeting to the brain because it is not taken up by other tissues such as liver and kidney (Lee et al., 2000).

The purpose of the current study was to evaluate the in vivo efficiency of intravenous administration of this Z-DEVDFMK nanomedicine in two prototypes of caspase-mediated cell death in the mouse, focal hemispheric ischemia/reperfusion and cerebellar developmental cell death. In addition, we directly demonstrated penetration and accumulation of the nanomedicine in the brain in the intact mouse by using intravital fluorescence microscopy.

\section{Materials and Methods}

\section{Materials}

Ultrapure chitosan hydrochloride salt Protasan UP CL $113(\mathrm{CS} \cdot \mathrm{HCl})$, number average molecular weight $\left(M_{\mathrm{n}}\right) 5.4 \times 10^{4}$, weight average molecular weight $\left(M_{\mathrm{w}}\right) 8.0 \times 10^{4}$ (determined by size exclusion chromatography with multiangle laser light scatter) (Lamarque et al., 2005), with $14 \%$ acetylation degree [determined by ${ }^{1} \mathrm{H}$ nuclear magnetic resonance (NMR)] (Fernandez-Megia et al., 2005) and the caspase inhibitor peptide Z-DEVD-FMK were purchased from FMC Biopolymers and Enzyme Systems, respectively. Pentasodium tripolyphosphate (TPP), trifluoroacetic acid (TFA), maleimidobenzoyl $N$-hydroxysuccinimide ester (MBS), Traut's reagent (2-iminothiolane), and polyethylene glycol 5000 monomethyl ether (MeO-PEG-OH, $M_{\mathrm{n}} 5055,\left(M_{\mathrm{w}}\right) 5088$, determined by matrix-assisted laser desorption/ionization-time-of-flight) were purchased from Sigma-Aldrich. Functional-grade purified antimouse CD71 (transferrin receptor) (clone: R17217, catalog no: 16-0711) antibody was received from eBioscience. Acetonitrile was purchased from Carlo Erba Reagenti. All other reagents used were of analytical or pharmaceutical grade.

\section{Synthesis of CS-PEG}

$\mathrm{CS} \cdot \mathrm{HCl}(100 \mathrm{mg}, 0.50 \mathrm{mmol})$ was dissolved in $\mathrm{H}_{2} \mathrm{O}(14.3 \mathrm{ml})$. MeOPEG-OCH $\mathrm{CO}_{2} \mathrm{H}$ has been synthesized from a commercially available MeO-PEG-OH according to known procedures (Royer and Anantharmaiah, 1979). MeO-PEG-OCH${ }_{2} \mathrm{CO}_{2} \mathrm{H}$ (17.8 mg, $3.47 \mu \mathrm{mol}, M_{\mathrm{n}} 5114$ ) and $N$-hydroxysuccinimide (NHS) $(2.03 \mathrm{mg}, 0.018 \mathrm{mmol})$ were then added to the solution. Finally, $N$-(3-dimethylaminopropyl)- $N^{\prime}-$ ethylcarbodiimide hydrochloride $(\mathrm{EDC} \cdot \mathrm{HCl})(27.1 \mathrm{mg}, 0.141 \mathrm{mmol})$ was added in portions due to its instability. The resulting solution was stirred at room temperature for $22 \mathrm{~h}$ and then was ultrafiltered (Amicon, YM30) and lyophilized to yield CS-g-PEG (CS-PEG) as white foam (105 $\mathrm{mg}$ ). The degree of PEGylation of this sample was $0.6 \%$ as determined by ${ }^{1} \mathrm{H}$ NMR $\left(2 \% \mathrm{DCl}\right.$ in $\left.\mathrm{D}_{2} \mathrm{O}\right)$.

\section{Synthesis of CS-PEG-BIO}

CS-PEG-BIO was synthesized following the same procedure as described above for CS-PEG from CS - $\mathrm{HCl}(100 \mathrm{mg}, 0.50 \mathrm{mmol}), \mathrm{HO}_{2} \mathrm{C}-\mathrm{PEG}-$ biotin (14.6 mg, $3.65 \mu \mathrm{mol}, M_{\mathrm{n}}$ 4030) (Fernandez-Megia et al., 2007), NHS (1.87 mg, $0.016 \mathrm{mmol})$, and $\mathrm{EDC} \cdot \mathrm{HCl}(27.0 \mathrm{mg}, 0.141 \mathrm{mmol})$. After ultrafiltration and lyophilization CS-PEG-BIO was obtained as white foam $(110 \mathrm{mg})$. The degree of PEGylation of this sample was $0.6 \%$ as determined by ${ }^{1} \mathrm{H}$ NMR $\left(2 \% \mathrm{DCl}\right.$ in $\left.\mathrm{D}_{2} \mathrm{O}\right)$.

\section{Preparation of TfRMAb-free chitosan nanospheres}

CS, CS-PEG, or CS-PEG-BIO nanospheres were prepared by the ionic gelation of TPP and CS, CS-PEG, or CS-PEG-BIO according to the procedure previously developed by Calvo et al. (1997) for the preparation of CS nanospheres.

Briefly, CS nanospheres were formed upon dropwise addition of $1 \mathrm{ml}$ of TPP aqueous solution $(0.4 \mathrm{mg} / \mathrm{ml})$ to $1 \mathrm{ml}$ of CS aqueous solution $(1.75 \mathrm{mg} / \mathrm{ml})$. Likewise, CS-PEG and CS-PEG-BIO (1 mg/ml each) nanospheres were prepared by dropwise addition of $0.4 \mathrm{ml}$ of TPP aqueous solution $(0.84 \mathrm{mg} / \mathrm{ml})$ to $1 \mathrm{ml}$ of each of the corresponding aqueous polymer solutions. These solutions were then stirred at medium speed at room temperature.

Z-DEVD-FMK-loaded nanospheres were obtained according to the same procedure, with the polymer/TPP ratio remaining unchanged. Z-DEVD-FMK was incorporated in the polymer solution before the addition of the TPP. To evaluate the effect of drug dosage on the inhibition of caspase-mediated cell death, two concentrations of the peptide were incorporated into the nanospheres. Briefly, Z-DEVD-FMK concentration in the nanosphere suspensions was either 200 or $800 \mathrm{ng} / \mathrm{ml}$. Nanospheres were isolated by ultracentrifugation $\left(10,000 \mathrm{rpm}, 4^{\circ} \mathrm{C}, 60 \mathrm{~min}\right)$ in the presence of $10 \mu \mathrm{l}$ of glycerol and then resuspended in water by manual shaking.

\section{Preparation of TfRMAb-conjugated nanospheres}

The SA/TfRMAb conjugates were prepared according to the procedure described by Yoshikawa and Pardridge (1992). Briefly, $1 \mathrm{mg}$ of SA was 
dissolved in $100 \mu \mathrm{l}$ of borate buffer containing $0.1 \mathrm{M}$ EDTA and $5 \mu \mathrm{l}$ of 2 -iminothiolane $(4 \mathrm{mg} / \mathrm{ml})$. After being stirred for $90 \mathrm{~min}$ at room temperature, thiolated streptavidin was purified by dialysis in $0.05 \mathrm{M}$ phosphate buffer, $\mathrm{pH}$ 6.5. In a parallel fashion, $100 \mu \mathrm{l}$ of TfRMAb solution ( 1 $\mathrm{mg} / \mathrm{ml}$ ) was stirred with $5 \mu \mathrm{l}$ of MBS solution $(5 \mathrm{mg} / \mathrm{ml}$ in dimethylformamide) for $30 \mathrm{~min}$ at room temperature to transform some of the amino groups into maleimide groups. Then, this TfRMAb solution was added to the above-described SA solution. After being stirred for $30 \mathrm{~min}$, the mixture was purified by dialysis.

SA/TfRMAb conjugate $(10 \mu \mathrm{l})$ was added to lyophilized CS-PEG-BIO nanospheres $(1 \mathrm{mg})$ previously resuspended in deionized water $(100 \mu \mathrm{l})$; this suspension was incubated for $30 \mathrm{~min}$. Loading of Z-DEVD-FMK was performed in the same conditions as for TfRMAb-free chitosan nanospheres (suspensions containing either 200 or $800 \mathrm{ng} / \mathrm{ml}$ ).

\section{Characterization of nanospheres}

Measurements of the size and zeta potential of the nanospheres were performed in triplicate by photon correlation spectroscopy and laser Doppler anemometry, respectively, using a Zetasizer Nanosystems 3000 HS (Malvern Instruments). The size measurements were performed at $25^{\circ} \mathrm{C}$ at a $90^{\circ}$ scattering angle, and each measurement was recorded for $180 \mathrm{~s}$.

The amount of drug loaded onto the nanospheres was calculated from the difference between the total amount of the peptide used for the encapsulation process and the quantity of the nonencapsulated drug, which still remained dissolved in the suspension medium. Briefly, the nanosphere suspension loaded with Z-DEVD-FMK was subjected to ultracentrifugation $\left(10,000 \mathrm{rpm}\right.$ at $4^{\circ} \mathrm{C}$ for $\left.1 \mathrm{~h}\right)$. The amount of free peptide was then measured in the clear supernatant by RP-HPLC method using a Hewlett-Packard Agilent 1100 apparatus with HP CHEMSTATION software and a C18 RP column $(250 \times 4.6 \mathrm{~mm}$; particle size $5 \mu \mathrm{m}$; Waters $)$. Water:acetonitrile (80:20) containing $0.1 \%$ TFA was used as the mobile phase with a flow rate of $1 \mathrm{ml} / \mathrm{min}$. Column effluent was monitored by UV absorption at $215 \mathrm{~nm}$ (Aktaş et al., 2005). The peptide loading capacity (LC) and the peptide association efficiency (AE) were calculated according to the following equations: \% LC $=100 \times$ (total peptide amount - free peptide amount $) /$ nanosphere weight and $\% \mathrm{AE}=100 \times$ (total peptide amount - free peptide amount)/total peptide amount.

\section{Evaluation of in vitro $Z$-DEVD-FMK release from} CS-PEG-BIO/SA-TfRMAb nanospheres

For release studies, isolated nanosphere suspensions $(1 \mathrm{mg} / \mathrm{ml})$ were incubated in $1 \mathrm{ml}$ of $\mathrm{PBS}, \mathrm{pH} 7.4$, at $37^{\circ} \mathrm{C}$ under light agitation. At varying time points, the supernatant was isolated by centrifugation at $10,000 \mathrm{rpm}$ for $20 \mathrm{~min}$ at $-4^{\circ} \mathrm{C}$, and the amount of Z-DEVD-FMK released was measured by RP-HPLC.

\section{Demonstration of nanosphere penetrance to the brain}

We used intravital fluorescent microscopy to monitor distribution of nanospheres in the intact mouse brain after systemic administration ( $n=6$ per conjugated or unconjugated nanosphere-injected group). For this purpose we loaded nanospheres with Nile red, which emits intense fluorescence, is not biodegradable, and can reliably be detected by spectrophotometry in addition to being efficiently loadable to nanospheres (Gessner et al., 2001). We chose Nile red as it was hydrophobic and hence could be retained longer on the nanospheres compared with the watersoluble Evans blue, which otherwise shares the above-described features with Nile red (Greenspan et al., 1985). Mice were anesthetized with isoflurane during surgery and with urethane $(750 \mathrm{mg} / \mathrm{kg}$, i.p., followed by $500 \mathrm{mg} / \mathrm{kg} 30 \mathrm{~min}$ later) during the experiment. Body temperature was monitored by a rectal probe and maintained at $37.0 \pm 0.2^{\circ} \mathrm{C}$ by a homeothermic blanket control unit (Harvard Apparatus). Pulse rate and oxygen saturation were monitored by an oxymeter using a mini Y clip on the left lower extremity (V3304 Tabletop Pulse Oximeter; Surgivet). A cranial window of $5 \times 5 \mathrm{~mm}$ was opened over parietotemporal cortex, leaving the dura intact to maintain physiological conditions. The window was sealed with dental acryl and then filled with artificial CSF at $37^{\circ} \mathrm{C}$ (in mM; $124 \mathrm{NaCl}, 5 \mathrm{KCl}, 1.25 \mathrm{NaH}_{2} \mathrm{PO}_{4}, 1.3 \mathrm{MgSO}_{4}, 2.4 \mathrm{CaCl}_{2}, 25 \mathrm{NaHCO}_{3}$, and 10 glucose; $\mathrm{pH}=7.4$ ). Fluorescent images were captured under a Nikon Eclipse E600 microscope with a modified stage at 100× magnification in a dark room by using camera (Nikon DXM1200) and NIS Elements Advanced Research (v.2.32, Nikon) software. Sequential images were recorded before (baseline) and 1, 5, 10, 20, and 30 min after the systemic injection of nanospheres, and then every $15 \mathrm{~min}$ for $3 \mathrm{~h}$ using the same exposure time and gain settings. Images were saved in TIFF format and the mean fluorescence intensity of the area imaged was calculated with the same software. Changes in fluorescence intensity from baseline were assessed after injection of the antibody-conjugated and unconjugated nanospheres. At the end of $1 \mathrm{~h}$, three mice of six (per group) were transcardially perfused with saline to flush intravascular content and, the brain, liver, and spleen were extracted. Tissues were immediately frozen and kept at $-80^{\circ} \mathrm{C}$ until use. Liver, spleen, and one hemisphere of each brain were used for the detection of tissue Nile red concentration spectrophotometrically. Fresh-frozen, coronal, $20-\mu \mathrm{m}$-thick sections were obtained from the other hemisphere ( $n=3$ per group). Sections were fixed with $96 \%$ alcohol for $10 \mathrm{~min}$, washed with PBS, and then immunostained with FITC-conjugated goat anti-rat IgG antibody (Sigma, 1:100 and 1:200) at room temperature for $60 \mathrm{~min}$ to detect the nanospheres conjugated with TfRMAb (rat IgG2a), coverslipped with mounting medium containing Hoechst 33258 to counterstain the nuclei. Negative controls were carried by omitting the anti-rat IgG antibody.

\section{Detection of tissue Nile red concentration}

Three groups (Nile red-loaded nanospheres conjugated with anti-TfR antibody, Nile red-loaded nanospheres unconjugated with TfRMAb, and the sham-operated group) were studied for detection of Nile red concentration in the brain, liver, and spleen ( $n=3$ mice per group) (Greenspan et al., 1985). One hemisphere was weighed and homogenized ( $25 \% \mathrm{w} / \mathrm{v})$ on ice in $25 \mathrm{~mm}$ HEPES, pH 7.4. Briefly, $3 \mathrm{ml}$ of $1 \%$ phosphoric acid was added to $500 \mu \mathrm{l}$ of homogenate to precipitate proteins. Then, $3 \mathrm{ml}$ of butanol was added to extract the lipid phase. The mixture was vortexed for $1 \mathrm{~min}$ at $2000 \mathrm{rpm}$ and then centrifuged at $2500 \times g$ for $15 \mathrm{~min}$. The upper butanol phase contained the extracted lipids. Nile red has an absorbance peak at $549 \mathrm{~nm}$ in butanol. Thus, the absorbance of the upper phase was measured with a spectrophotometer (Shimadzu UV 1700) at $549 \mathrm{~nm}$ and the amount of Nile red was determined by a calibration curve.

\section{Focal cerebral ischemia model}

To investigate the pharmacological activity of Z-DEVD-FMK-loaded nanospheres on brain ischemia, the temporary intraluminal filament occlusion method was used. Swiss albino mice weighing 18-22 g were housed under diurnal lighting conditions ( $12 \mathrm{~h}$ darkness and $12 \mathrm{~h}$ light). Before the experiment, the mice were fasted overnight but allowed ad libitum access to water. Animal housing, care, and application of experimental procedures were all done in accordance with institutional guidelines. All animal experiments described in this and the previous section were approved by Hacettepe University Ethics Committee (2006-71). Mice were anesthetized with $50 \mathrm{mg} / \mathrm{kg}$ intraperitoneal ketamine (Ketalar; Parke-Davis) and $10 \mathrm{mg} / \mathrm{kg}$ intraperitoneal xylazine (Alfazyne; Alfasan). Body temperature was monitored by a rectal probe and maintained at $37.0 \pm 0.2^{\circ} \mathrm{C}$ by a homeothermic blanket control unit (Harvard Apparatus). Systolic blood pressure was monitored noninvasively by using a cuff and tail probe (NIBP controller; AD Instruments). Pulse rate and oxygen saturation were monitored by an oxymeter using a mini Y clip on the left lower extremity (V3304 Tabletop Pulse Oximeter; Surgivet).

Proximal occlusion of the right middle cerebral artery (MCA) was performed with a nylon filament, as described previously (Huang et al., 1994). Briefly, after a midline incision, the right common carotid artery and external carotid artery were ligated with a 5-0 silk suture. To induce ischemia, a nylon filament (8-0) was inserted into the common carotid artery through a small incision proximal to the bifurcation and advanced in the internal carotid artery up to the origin of MCA $(10 \mathrm{~mm}$ from the bifurcation) (Gürsoy-Ozdemir et al., 2000). The distal $3 \mathrm{~mm}$ of 8-0 filament was coated with silicone resin/hardener mixture (Xantropen M Haereus Kulzer, and Optosil-Xantropen Activator, Bayer). A flexible probe (PF-318 of PeriFlux PF 2B; Perimed) was placed over the skull (2 $\mathrm{mm}$ posterior, $6 \mathrm{~mm}$ lateral to the bregma) away from large pial vessels to monitor the regional cerebral blood flow (rCBF) by laser Doppler flow- 
metry. After obtaining a stable $10 \mathrm{~min}$ epoch of preischemic $\mathrm{rCBF}$, the MCA was occluded. rCBF was monitored during $20 \mathrm{~min}$ of ischemia and the first $10 \mathrm{~min}$ of reperfusion. Reperfusion was accomplished by pulling the filament back.

\section{Neuroprotection study groups}

To evaluate the neuroprotective effect of the nanospheres, five groups of mice were subjected to $2 \mathrm{~h}$ of proximal MCA occlusion and $24 \mathrm{~h}$ of reperfusion. The control group $(n=8)$ received drug unloaded (i.e., blank) CS-PEG-BIO/SA-TfRMAb nanospheres. The TfRMAb-free group $(n=6)$ received CS-PEG-BIO nanospheres (unconjugated with TfRMAb) loaded with $188 \mathrm{ng}$ of peptide/mg nanospheres. The low-dose group $(n=6)$ received CS-PEG-BIO/SA-TfRMAb nanospheres loaded with $50 \mathrm{ng} / \mathrm{mg}$ Z-DEVD-FMK. The high-dose group $(n=6)$ received CS-PEG-BIO/SA-TfRMAb nanospheres loaded with $188 \mathrm{ng} / \mathrm{mg}$ Z-DEVD-FMK. In these four groups, nanospheres (1 mg of nanosphere in $100 \mu$ l of saline) were administered via the tail vein before inducing the ischemia. The post-treatment group $(n=6)$ received CSPEG-BIO/SA-TfRMAb nanospheres loaded with $188 \mathrm{ng} / \mathrm{mg}$ Z-DEVDFMK $2 \mathrm{~h}$ after ischemia just before reperfusion. Twenty-four hours after reperfusion, mice were killed and the infarct volumes were calculated as described below.

\section{Neurological evaluation}

At $24 \mathrm{~h}$ postischemia, neurological deficits were assessed by an observer blinded to the identity of treatment and scored as described previously (Huang et al., 1994): 0, no observable neurological deficits (normal); 1, failure to extend left forepaw on lifting the whole body by the tail (mild); 2 , circling to the contralateral side (moderate); 3 , leaning to the contralateral side at rest or no spontaneous motor activity (severe).

\section{Evaluation of infarct volume}

After $2 \mathrm{~h}$ of ischemia and $24 \mathrm{~h}$ of reperfusion, mice were anesthetized with a lethal dose of chloral hydrate $(400 \mathrm{mg} / \mathrm{kg}$, i.p.). Mice were transcardially perfused with heparin followed by $4 \%$ paraformaldehyde and then decapitated. Brains were stored in $4 \%$ paraformaldehyde for $48 \mathrm{~h}$ and then sectioned coronally to 2-mm-thick slices starting from the frontal pole. Slices were embedded in paraffin. Five-micrometer-thick coronal sections were prepared from the posterior surface of each slice and stained with hematoxylin and eosin.

The infarct was defined as the area showing reduced eosin staining under light microscopy. The boundaries between areas of infarction and adjacent normal brain were clearly delineated. The size of infarct area was measured using image analysis software (NIH ImageJ 1.59). The areas of noninfarcted tissue ipsilateral and contralateral to the occluded side were measured. Infarct area was calculated using an indirect method, in which the noninfarcted region in the ischemic hemisphere was subtracted from the total surface area of the contralateral hemisphere (Swanson et al., 1990). Infarct volume was then calculated by multiplying each sequential infarct area by $2 \mathrm{~mm}$, which is the distance between sections. The infarct volume is presented in cubic millimeters.

\section{Caspase- 3 activity in ischemic brain tissue}

To evaluate the effect of nanospheres on caspase- 3 activity in the ischemic hemisphere, three additional mice each from the control group, TfRMAb-free group, high-dose group, and a sham-operated group (see below, "Cerebellar caspase-3 activity") were studied. In all groups, the nanospheres were administered via tail vein before inducing ischemia. After $2 \mathrm{~h}$ of ischemia and $1 \mathrm{~h}$ of reperfusion, the mice were killed and their brains were assessed for caspase- 3 activity as described below. One hour of reperfusion was selected because caspase-3 activity reportedly peaks at this time point (Ma et al., 1998, 2001).

Brains were weighed and homogenized $(20 \% \mathrm{w} / \mathrm{v})$ on ice using homogenizer in a buffer containing 25 mM HEPES, pH 7.4, 2 mM EDTA, 2 mm EGTA, 2 mм DTT, 5 mм $\mathrm{MgCl}_{2}, 0.1 \%$ Triton X-100, and $10 \mu \mathrm{g} / \mathrm{ml}$ protease inhibitor mixture. The homogenates were centrifuged at $4^{\circ} \mathrm{C}$, $12,000 \times g$ for $20 \mathrm{~min}$. The clear supernatants were used for caspase-3 activity and protein determination. All assays were done at least in duplicate. Caspase- 3 activity was determined using the ApoScreen Kit from ICN Biomedicals. Briefly, $25 \mu \mathrm{l}$ of sample was added to a well in a 96-well plate. Each well already contained $100 \mathrm{~mm}$ HEPES, pH 7.4, and $2 \mathrm{~mm}$ DTT. The reaction was initiated by the addition of the fluorogenic caspase-3 substrate ( $N$-acetyl)-Asp-Glu-Val-Asp-7-amino-4-trifluoromethylcoumarin (Ac-DEVD-AFC) (final concentration $200 \mu \mathrm{M}$ ). To confirm that enzyme activity was related to caspase-3, parallel samples were incubated for $25 \mathrm{~min}$ with the competitive inhibitor Z-DEVD-FMK (final concentration $40 \mu \mathrm{M}$ ) before addition of the substrate. Activity was measured at baseline and after $35 \mathrm{~min}$ using the fluorescence level (excitation 400, emission $505 \mathrm{~nm}$ ) detected by a SpectraMax M2 spectrophotometric plate reader and SOFTmax Pro 3.1.1 software (Molecular Devices). Caspase- 3 activity was calculated from the slope as fluorescence units per milligram of protein per minute of reaction time as a difference between substrate utilization velocity in the samples with and without caspase-3 inhibitor. This measurement was then converted to picomoles of substrate cleaved per milligram of protein per minute, based on a standard curve for amino-4-trifluoromethylcoumarin. Protein concentration in the supernatant was determined by the Bradford assay.

\section{Cerebellar caspase- 3 activity}

We also tested the efficiency of the nanospheres loaded with Z-DEVDFMK to translocate into the brain and inhibit neonatal cerebellar caspase activity. Postnatal day 17 was chosen to study the efficiency of nanospheres because, at this time point, cerebellar apoptosis is still active but the BBB has been closed (Wood et al., 1993; Hallmann et al., 1995). To confirm that the BBB was closed, BBB-impermeable Evans blue (Sigma, $0.1 \mathrm{ml}$ of $4 \%$ solution) was injected into tail vein $1 \mathrm{~h}$ before mice were killed. To confirm the presence of caspase- 3 activity on postnatal day 17, sections were immunostained with an antibody against the active cleaved form of caspase-3 (caspase-3-p20, Cell Signaling Technology). Mice were deeply anesthetized with an overdose of chloral hydrate (400 mg/kg, i.p.). The brain was removed quickly, and the cerebellum was separated. Cerebella were fixed in $4 \%$ paraformaldehyde solution for $1 \mathrm{~d}$ followed by cryoprotection in $30 \%$ sucrose solution. Twenty-micrometer-thick cerebellar coronal sections were cut on a cryostat. Sections were immunostained with the rabbit polyclonal caspase-3-p20 (1:200) and followed by goat anti-rabbit Cy2 antibody (1:200, Jackson Immunoresearch). Sections were examined under a fluorescence microscope (Nikon Eclipse E600) with appropriate filter sets.

After demonstrating that the BBB was well intact and that there was significant caspase-3-p20 immunostaining in the cerebellum, cerebellar caspase- 3 activity was biochemically detected. Three groups of neonatal mice ( $n=3$ per group) were studied: the sham-operated group, which received vehicle only; the TfRMAb-free group, which received CS-PEGBIO nanospheres unconjugated with TfRMAb but loaded with 188 ng/mg Z-DEVD-FMK; and the high-dose group, which received CSPEG-BIO/SA-TfRMAb nanospheres loaded with 188 ng/mg Z-DEVDFMK. In all groups, the nanospheres were administered via the tail vein. Cerebella were removed $3 \mathrm{~h}$ after treatment and stored at $-80^{\circ} \mathrm{C}$. Cerebellar caspase- 3 activity was determined by the fluorometric method described above.

Sham operations were performed by paratracheal dissection and exposition of the common carotid and internal carotid arteries for the detection of caspase- 3 activity. The sham operation was performed by the same anesthesia protocol.

\section{Statistical analysis}

Data are expressed as mean \pm SEM. Body weight, body temperature, blood pressure, rCBF, neurological deficit score, infarct volume, and caspase-3 activity values were compared with the Kruskal-Wallis test. Statistically significant data were further analyzed with the Mann-Whitney $U$ test. The percentage change in fluorescence intensity between the sequential images acquired during intravital microscopy experiments was compared by Wilcoxon signed rank test. The percentage change between the groups was compared by Mann-Whitney $U$ test. A $p$ value of $\leq 0.05$ was regarded as statistically significant.

\section{Results}

Nanosphere preparation and characterization

Z-DEVD-FMK was successfully loaded onto the nanospheres. Particle size, zeta potential, Z-DEVD-FMK AE, Z-DEVD-FMK 
Table 1. Characteristics of Z-DEVD-FMK-loaded nanospheres

\begin{tabular}{|c|c|c|c|c|c|}
\hline Z-DEVD-FMK concentration ( $\mathrm{ng} / \mathrm{ml})$ & Particle size (nm) & Zeta potential (mV) & $\% \mathrm{AE}$ & $\% \mathrm{LC}$ & Loaded peptide (ng/mg nanospheres) \\
\hline Blank & $610 \pm 2$ & $+22 \pm 3$ & & & \\
\hline 200 & $650 \pm 2$ & $+20 \pm 4$ & $25 \pm 1$ & $0.005 \pm 0.038 \times 10^{-3}$ & 50 \\
\hline 800 & $637 \pm 2$ & $+18 \pm 4$ & $23 \pm 1$ & $0.019 \pm 0.022 \times 10^{-3}$ & 188 \\
\hline
\end{tabular}

A

\section{Kinetics of vascular and parenchymal distribution of nanospheres}

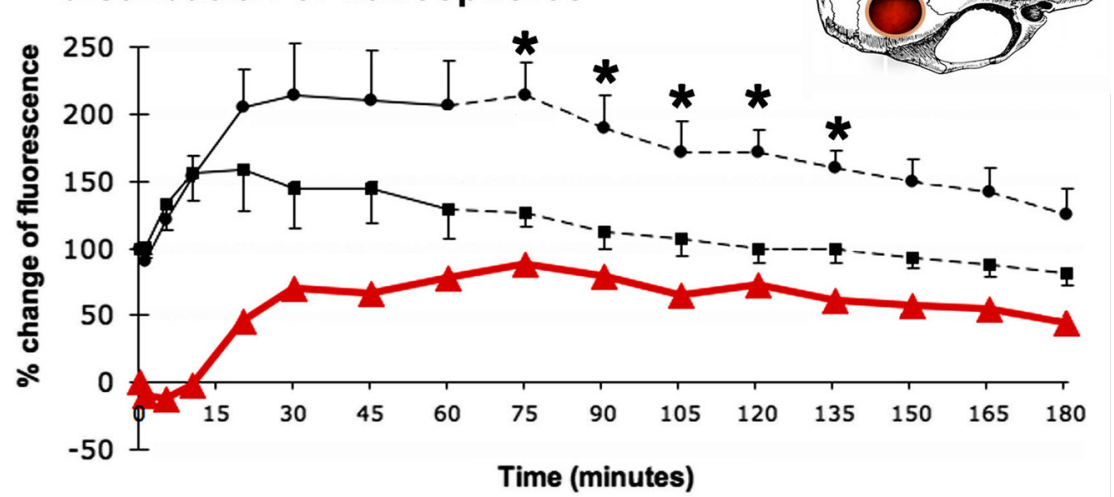

Time (minutes)

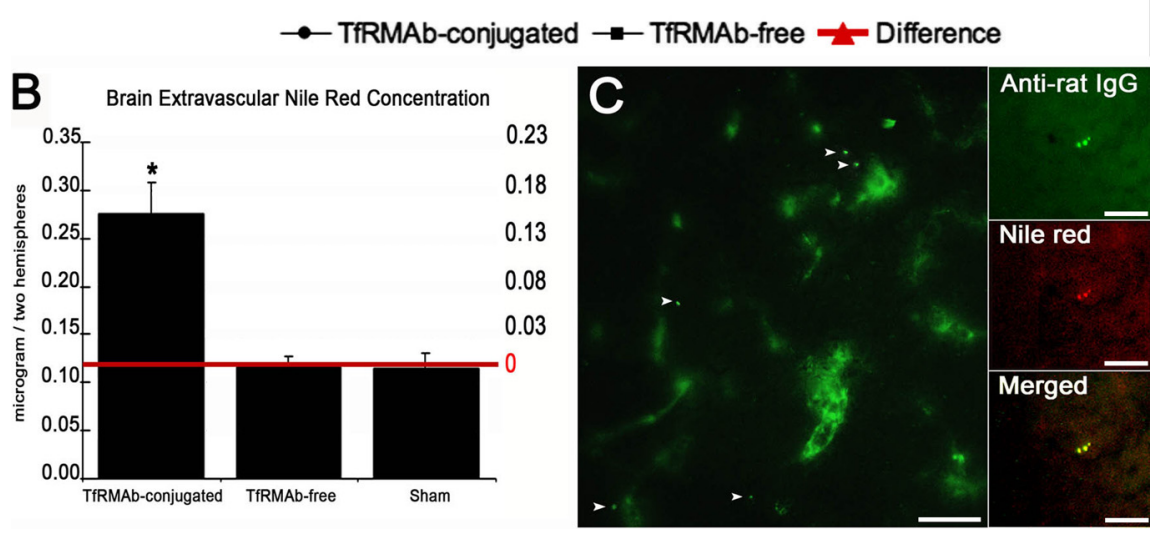

Figure 2. A, Nanospheres are rapidly transported to brain parenchyma after systemic administration. The graph illustrates the change in fluorescence recorded from the brain over the course of $3 \mathrm{~h}$ after injection of Nile red-loaded to TfRMAb-conjugated (O) or unconjugated $(\boldsymbol{\square})$ nanospheres. The difference between the two lines ( $\boldsymbol{\Lambda}$, red line) reflects the fluorescence coming from the nanospheres within the parenchyma and illustrates the time course of nanosphere penetrance to the brain. ${ }^{*}$ The difference between the unconjugated and conjugated nanospheres was significant at 75-135 min time points ( $p<0.05 ; p=0.08$ for the next $45 \mathrm{~min}$ ). Dashed lines indicate that the number of animals followed up after the $1 \mathrm{~h}$ time point was reduced from six to three. $\boldsymbol{B}$, Nile red concentration in brain postvascular tissue increased only when TfRMAb-conjugated nanospheres were administered. The graph illustrates spectrophotometric measurements at $549 \mathrm{~nm}$ from brain homogenates obtained $1 \mathrm{~h}$ after injection of TfRMAb-conjugated or unconjugated nanospheres or from sham-operated mice. Only values above the horizontal red line, below which values correspond to the tissue background readings, were taken into consideration. ${ }^{*} p<0.05$ compared with the other groups. C, We confirmed penetration of the nanospheres to the parenchyma by fluorescent microscopy on brain sections obtained $1 \mathrm{~h}$ after injection. FITC-conjugated anti-rat lgG antibody (green) labeled the nanospheres bearing TfRMAb, clearly demonstrating that the nanospheres were dispersed within the extracellular space outside the vessel lumens. Vessels were visualized by nonspecific labeling obtained with a high concentration of the antibody. Some FITC-conjugated nanospheres exhibited green as well as red fluorescence because they had not released all the Nile red loaded within an hour (right). A lower concentration of the antibody was used to stain these sections; hence, vessels were not labeled. Scale bars: C, left panel, $15 \mu \mathrm{m} ; \boldsymbol{C}$, right panels, $5 \mu \mathrm{m}$. The mouse skull picture was modified from http://www.informatics.jax.org/greenbook/images/13-1.jpg.

LC values, and loaded peptide amounts are given in Table 1. As the incorporated amount of the peptide increased, drug loading and particle sizes increased slightly, whereas zeta potential decreased due to the negative charge of the peptide. The loaded amount of the peptide proportionally increased from 50 to 188 $\mathrm{ng}$, as the amount of the peptide used in nanosphere preparation was raised from 200 to $800 \mathrm{ng} / \mathrm{ml}$.
In vitro release of Z-DEVD-FMK from nanospheres

There was no detectable release $(n=3)$ in vitro from the low-dose sample, which was possibly due to the strong ionic interaction of the small amount of the negatively charged peptide with the polymer. For the high-dose sample, an initial burst release $(7 \pm 0.2 \%)$ occurred, which likely corresponded to the release of the peptide bound at the surface of the nanospheres. This was followed by a sustained release, which yielded discharge of $43 \pm 0.9 \%$ of loaded Z-DEVD-FMK by $24 \mathrm{~h}(n=3)$ (Aktaş et al., 2005).

\section{Nanospheres rapidly penetrate brain tissue in vivo}

Fluorescence intensity of nanospheres loaded with Nile red was strong enough to monitor nanosparticles in the intact mouse brain with intravital microscopy ( $n=12$ mice). We were able to differentiate fluorescence coming from the nanosparticles within the brain parenchyma from those in circulation by comparing the recordings obtained after injection of nanospheres unconjugated $(n=6)$ and conjugated $(n=6)$ with TfRMAb, which are unable and able to cross the BBB, respectively (Fig. 2). We observed that fluorescence from the unconjugated nanospheres in circulation peaked at $10 \mathrm{~min}$ after systemic administration $(p=0.04)$, made a plateau for the next $10 \mathrm{~min}(p=$ 0.89 ; $p$ values denote the significance of the variation observed between consecutive values) and disappeared by $2 \mathrm{~h}$ ( $p=$ 0.04 ), whereas stronger fluorescence from the conjugated nanospheres continued to increase after the first $10 \mathrm{~min}(p=0.04)$, made a plateau between 20 and $75 \mathrm{~min}$ $(p=0.69)$, and was largely sustained by the end of $3 \mathrm{~h}$ follow-up period. Subtraction of fluorescence recorded after injection of the unconjugated nanospheres from that of the conjugated nanospheres disclosed that nanospheres started penetrating into parenchyma after the 10th min of injection and reached a peak at $75 \mathrm{~min}$.

We confirmed penetration of the nanospheres to parenchyma by fluorescent microscopy on brain sections obtained $1 \mathrm{~h}$ after injection. FITC-conjugated anti-rat IgG antibody labeled the nanospheres bearing TfRMAb, clearly demonstrating that the nanospheres were transported across the BBB and dispersed within the extracellular space outside the vessel lumens (Fig. 2C). 

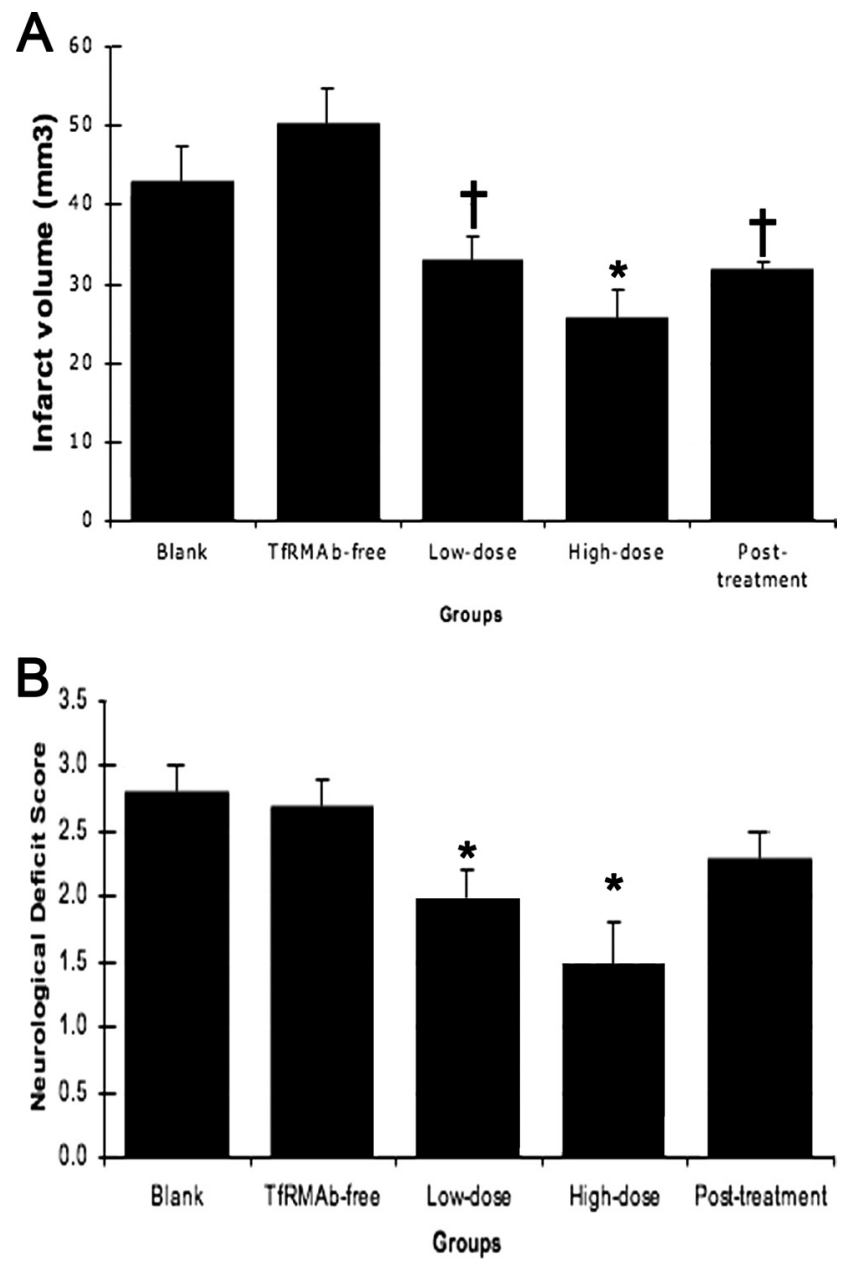

Figure 3. Treatment with Z-DEVD-FMK-Ioaded CS-PEG-BIO/SA-TfRMAb nanospheres decreases infarct size. Mice subjected to $2 \mathrm{~h}$ of MCA occlusion were treated intravenously with nanospheres loaded with either a low or a high dose of Z-DEVD-FMK. Nanospheres were injected just before ischemia except in the post-treatment group, which received nanospheres just before reperfusion. The controls included blank nanospheres lacking Z-DEVD-FMK and nanospheres containing a high dose of Z-DEVD-FMK but not conjugated with TfRMAb. $A$, The infarct volume was detected $24 \mathrm{~h}$ after reperfusion. $\boldsymbol{B}$, Changes in neurological deficit paralleled the infarct volume data. *Significant difference compared with the blank and the TfRMAb-free group. ${ }^{\dagger}$ Significant difference compared with the TfRMAb-free group.

Some nanospheres exhibited green as well as red fluorescence, whereas some other nanospheres displayed only green fluorescence possibly because they had released most of the Nile red loaded within an hour. Because of the considerable red background fluorescence mimicking nanospheres (e.g., lipofucsin and perhaps lipid droplets stained with Nile red) it was not feasible to distinguish Nile red-loaded nanospheres without using the FITC-conjugated anti-rat IgG antibody. Accordingly, some of the nanospheres emitting red fluorescence may have gone unidentified if they were detached from the TfRMAb.

We also measured Nile red concentration in brain, liver, and spleen tissue homogenates $1 \mathrm{~h}$ after injection of unconjugated or conjugated nanospheres ( $n=3$ per group). The circulation was, however, flushed with saline before sacrificing the animals therefore measurements reflected the Nile red accumulated in the parenchyma without any contribution from nanospheres within the circulation. In these conditions, we found that Nile red was present only in the brain of mice injected with nanospheres conjugated with TfRMAb, which is specific to the transferrin recep-
Table 2. Physiological parameters of groups subjected to ischemia

\begin{tabular}{lrlll}
\hline Group & $\begin{array}{l}\text { Blood pressure } \\
(\mathrm{mmHg})\end{array}$ & $\begin{array}{l}\text { rCBF during } \\
\text { ischemia }(\%)\end{array}$ & $\begin{array}{l}\text { Pulse rate } \\
(\mathrm{bpm})\end{array}$ & $\begin{array}{l}\text { Tissue oxygen } \\
\text { saturation (\%) }\end{array}$ \\
\hline TfRMAb-free & $89 \pm 4(n=6)$ & $26 \pm 4$ & $281 \pm 20$ & $94 \pm 1$ \\
Low-dose $_{\text {High-dose }}^{89 \pm 5(n=5)}$ & $23 \pm 5$ & $283 \pm 15$ & $93 \pm 1$ \\
Blank $^{a}$ & $89 \pm 6(n=6)$ & $18 \pm 3$ & $246 \pm 21$ & $92 \pm 1$ \\
TfRMAb-free $^{a}$ & $95 \pm 5(n=2)$ & $26 \pm 4$ & $293 \pm 22$ & $95 \pm 3$ \\
High-dose $^{a}$ & $100 \pm 5(n=2)$ & $26 \pm 5$ & $311 \pm 13$ & $95 \pm 2$ \\
Post-treatment & $91 \pm 2(n=6)$ & $24 \pm 2$ & $248 \pm 14$ & $94 \pm 1$
\end{tabular}

${ }^{a}$ Groups of which caspase- 3 activity was assessed in the ischemic hemisphere. Values are given as mean \pm SEM Means were not significantly different $(p>0.05)$.

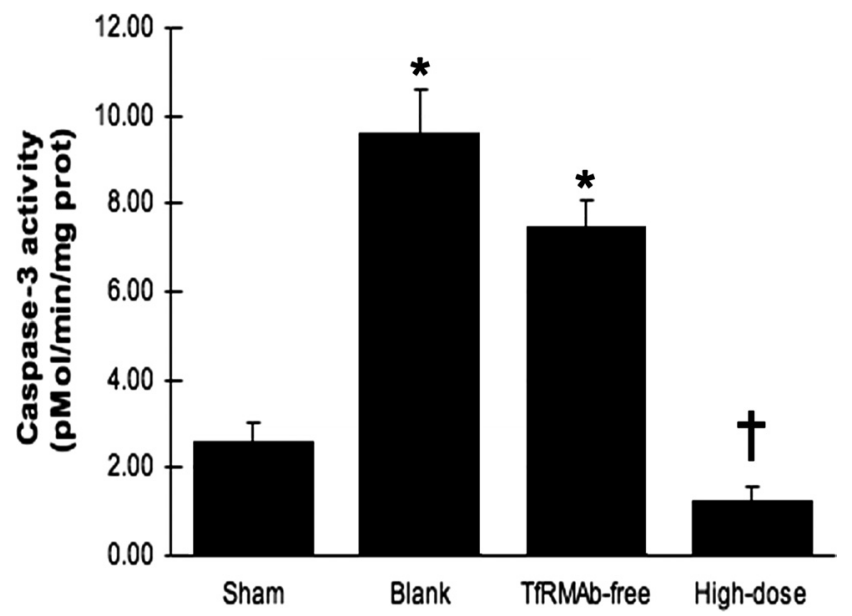

Figure 4. Caspase inhibitor-loaded nanospheres suppress the ischemia-induced increase in caspase-3 activity. Caspase-3 activity was detected in hemispheres obtained from mice subjected to either sham surgery or $2 \mathrm{~h}$ MCA occlusion and $1 \mathrm{~h}$ reperfusion. Nanospheres loaded with a high dose of Z-DEVD-FMK and conjugated with TfRMAb antibody (High-dose) significantly inhibited caspase-3 activity whereas nanospheres not loaded with the peptide (Blank) or unconjugated with TfRMAb (TfRMAb-free) were ineffective $(p<0.05)$. * Significant difference when compared with the sham-operated group. ${ }^{\dagger}$ No significant difference when compared with the sham-operated group. prot, Protein.

tor type 1 on cerebral vasculature and is not taken up by liver (Lee et al., 2000) (Fig. 2B). Measurements obtained from the mice treated with unconjugated nanospheres were not significantly different from the values obtained from sham-operated mice $(n=3)$. We also did not detect any Nile red accumulation in the liver and spleen tissue of mice treated with either conjugated or unconjugated nanospheres.

\section{Z-DEVD-FMK-loaded nanospheres inhibit caspase-3 activity} and provide neuroprotection

Intravenously administered nanospheres loaded with Z-DEVDFMK, either at a high or low dosage, significantly decreased the infarct volume compared with the group receiving peptide-free nanospheres (blank) or TfRMAb-free nanospheres (Fig. 3A). After $2 \mathrm{~h}$ of ischemia and $24 \mathrm{~h}$ of reperfusion, the infarct volume of the control groups administered with blank CS-PEG-BIO/ SA-TfRMAb or TfRMAb-free nanospheres were $43 \pm 4 \mathrm{~mm}^{3}(n=$ $8)$ and $50 \pm 4 \mathrm{~mm}^{3}(n=6)$, respectively $(p>0.05)$. The infarct volumes of the animals receiving the low dose or the high dose of Z-DEVD-FMK before ischemia were $33 \pm 3 \mathrm{~mm}^{3}(n=6)$ and $26 \pm 4 \mathrm{~mm}^{3}(n=6)(p<0.05)$, respectively. Post-treatment with the high dose of Z-DEVD-FMK $2 \mathrm{~h}$ after ischemia still provided neuroprotection; the infarct volume was $32 \pm 2 \mathrm{~mm}^{3}$ in this group $(n=6)(p<0.05)$. 

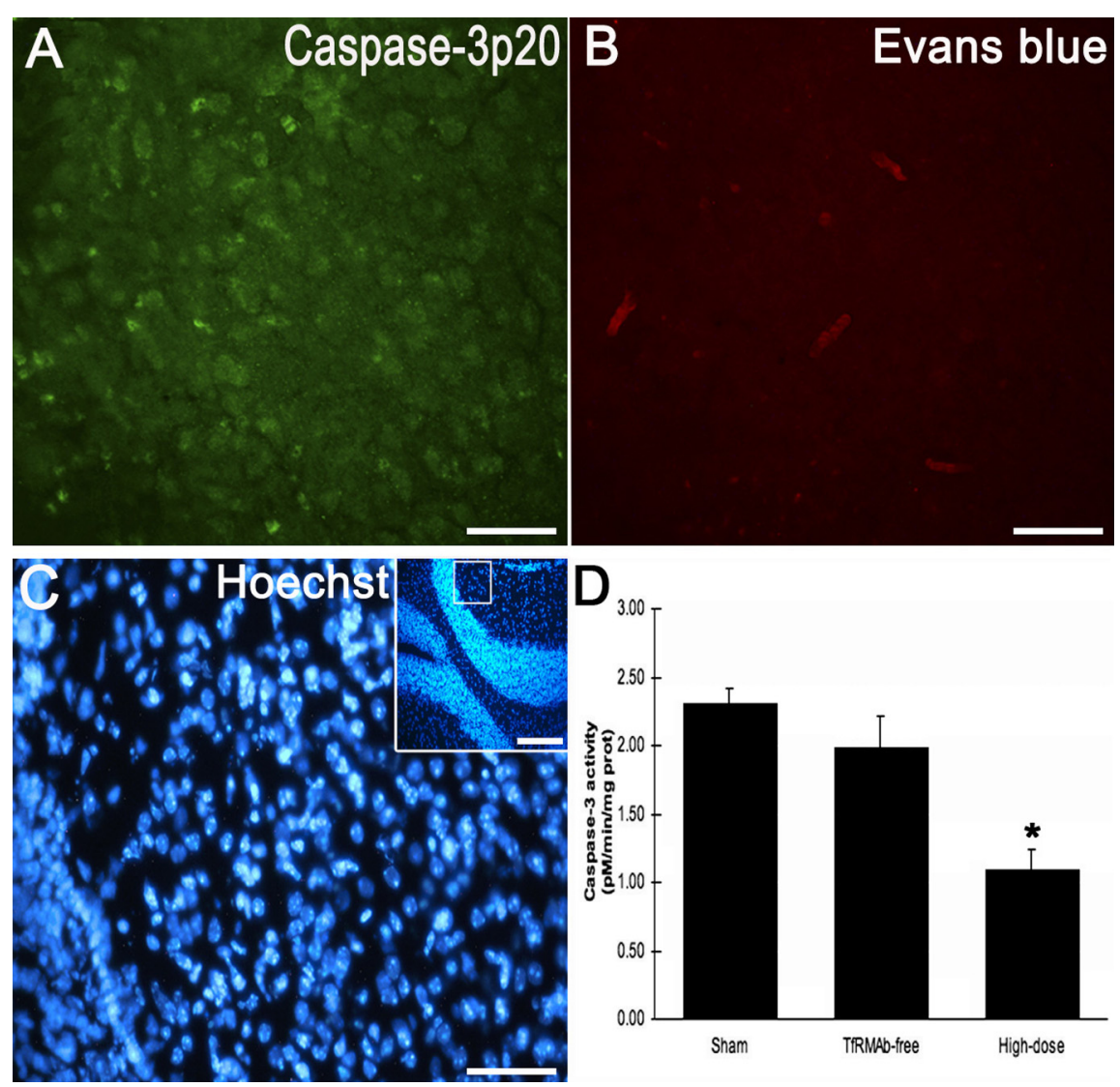

Figure 5. Cerebellum from 17-d-old neonatal mice had a mature BBB and exhibited caspase activity due to ongoing developmental cell death. $\boldsymbol{A}-\boldsymbol{C}$, Several cerebellar cells were immunoreactive for the active cleaved form of caspase-3, caspase-3p20. Hoechst 33258 staining of the same area identified cell nuclei and illustrated the cerebellar layers. Boxed area in the inset ( $\boldsymbol{C}$ corresponds to the area shown in $\boldsymbol{A}$-C. Intravenously injected BBB-impermeable fluorescent dye, Evans blue (red), did not leak into the parenchyma but was retained within vessels, showing that the BBB was intact. D, Caspase inhibitor-loaded CS-PEG-BI0/SATfRMAb nanospheres suppress cerebellar caspase-3 activity. Physiological caspase-3 activity was detected in cerebella obtained from postnatal day 17 mice subjected to sham surgery. Treatment with nanospheres loaded with a high dose of Z-DEVD-FMK and conjugated with TfRMAb antibody (High-dose) significantly inhibited caspase-3 activity whereas nanospheres unconjugated with TfRMAb (TfRMAb-free) were ineffective $(p<0.05)$. * Significant difference compared with the sham and the TfRMAb-free group Scale bars: $\mathbf{A}-\boldsymbol{C}, 30 \mu \mathrm{m}$; , inset, $100 \mu \mathrm{m}$. prot, Protein.

Treatment with the nanospheres also decreased neurological deficits. Neurological deficit scores $24 \mathrm{~h}$ after reperfusion were $2.8 \pm 0.2$ for the blank group $(n=5), 2.6 \pm 0.2$ for the TfRMAbfree group $(n=6), 2.0 \pm 0.2$ for the low-dose group $(n=6)$, $1.5 \pm 0.3$ for the high-dose group $(n=4)$, and $2.3 \pm 0.2$ for the post-treatment group $(n=6)(p<0.05)$ (Fig. $3 B)$.

$\mathrm{rCBF}$, pulse rate, rectal temperature, and tissue oxygen saturation were monitored in all groups (Table 2). rCBF decreased to $\sim 20 \%$ of the baseline after MCA occlusion in all groups. After reperfusion, $\mathrm{rCBF}$ increased to $90-100 \%$ of the baseline in a time interval of $10 \mathrm{~min}$. There were no significant blood flow differences between the blank, TfRMAb-free, high-dose, and low-dose groups. The mean arterial blood pressure, pulse rate, rectal temperature, and oxygen saturation of groups were also not different. Thus, reduction in the infarct volume and neurological scores by the caspase inhibitor-based nanomedicine could be attributed to its neuroprotective action but not to any possible hemodynamic effects or systemic changes.

In line with the above infarct data, treatment with high-dose Z-DEVD-FMK nanospheres dramatically suppressed caspase-3 activity in the ischemic hemisphere $(p<0.05)$ (Fig. 4).
Z-DEVD-FMK-loaded nanospheres inhibit cerebellar caspase- 3 activity in neonatal mice

Since ischemia causes BBB disruption, there was a possibility that nanospheres could pass into ischemic tissue through disrupted BBB without a need for the TfRMAbdecorated carrier system, although the data from TfRMAb-free group did not suggest this. To unequivocally show that nanospheres can efficiently translocate across the intact BBB, the caspase- 3 activity during developmental cell death in cerebellar tissue was used as a proof of concept.

We first detected diffuse caspase-3-p20 immunoreactivity on postnatal day 17 (Fig. $5 A)$. The $\mathrm{BBB}$ was intact at that time period as indicated by the exclusion of BBBimpermeable Evans blue from the cerebellar parenchyma (Fig. 5B). Hence, postnatal day 17 was confirmed as an appropriate time point to investigate the penetration of peptide-loaded nanospheres into the brain through an intact BBB. In line with immunohistochemical findings, we found substantial caspase- 3 activity in the cerebellum of the sham-operated group. This caspase- 3 activity was significantly inhibited in the high-dose-treated group but not in the TfRMAb-free nanospheretreated group $(p<0.05)$ (Fig. 5D).

\section{Discussion}

Ischemic stroke is a major health problem. Stroke is, indeed, the third most common cause of death in developed countries, exceeded only by coronary heart disease and cancer. Annually, 15 million people worldwide suffer a stroke. Of these, 5 million die, and another 5 million are left permanently disabled, placing a burden on family and community. Several agents acting on excitotoxic or free radical mechanisms have been tested in $>30$ clinical trials, but none have been successful (Kidwell et al., 2001; Green et al., 2003). The causes of failure are probably multiple, but one possible reason is that these agents act on mechanisms that are activated at the onset of stroke. Therefore, in most of the patients, the damage via these mechanisms had already been inflicted well before the administration of the neuroprotective agent. Accordingly, downstream cascades in ischemic cell death have recently been the focus of interest. One of these targets is caspase-3, the executioner caspase activated by several death pathways, which then degrades many proteins vital for cell survival (Thornberry and Lazebnik, 1998; Zhang and $\mathrm{Xu}, 2002)$. In several rodent models of focal or global ischemia, inhibition of caspase-3 has appeared as a promising target (Hara et al., 1997; Chen et al., 1998; Ma et al., 2001). However, the currently available capase- 3 inhibitors are small peptides that are unable to cross the BBB (Callus and Vaux, 2007). Accordingly, these agents can only be administered by intracerebroventricular injection, which is one of the obstacles hindering translation of the progress in this area to the clinic. Of note, a caspase inhibitor, Q-VD-oph has recently been proposed to penetrate the brain after systemic de- 
livery based on the observations that it successfully reduced damage after cerebral hypoxia/ischemia (Braun et al., 2007; Renolleau et al., 2007). Although this is an exciting possibility, information regarding the $\mathrm{BBB}$ permeability of this dipeptide should be cautiously considered until there is direct evidence showing that it efficiently crosses the BBB because Q-VD-oph might also provide neuroprotection by its action on vascular targets.

One potential way to overcome the limitations on drug delivery to CNS is the utilization of new techniques that will enable penetration of small peptides through the $\mathrm{BBB}$. We recently developed a nanotechnology based on the targeted delivery of the caspase-3 inhibitor to the brain via biocompatible chitosan nanospheres. In that study, we documented that Z-DEVD-FMK-loaded chitosan nanospheres conjugated with anti-mouse transferrin receptor (CD71) antibody were able to cross the BBB by binding to the endothelial transferrin receptor in the mouse (Aktaş et al., 2005) (note that OX26 was used as a generic term for antitransferrin receptor antibodies at that time but its use is now correctly limited to an anti-rat transferrin receptor antibody) (Lee et al., 2000). However, we previously did not investigate whether or not this drug delivery system could have beneficial pharmacological consequences. In the present study, we have unequivocally demonstrated that, when given by a systemic route, nanospheres can rapidly carry and deliver sufficient amounts of the Z-DEVD-FMK peptide to the brain to significantly inhibit caspase-3 activity in the ischemic brain, as well as in the normal neonatal brain.

Intravital microscopy studies provided the opportunity to directly demonstrate that nanospheres are rapidly transported to the brain parenchyma starting 10 min after systemic administration. We used Nile red-loaded instead of Z-DEVD-FMK-loaded nanospheres since Z-DEVD-FMK was not technically suitable for intravital fluorescent microscopy experiments and chemical detection in the tissue. However, we assume that the transport kinetics for both type nanospheres are similar because the transport rate is essentially determined by interactions between the TfRMAb and transferrin receptor in addition to ability of cationic chitosan to interact with negative charges on the endothelium. We have confirmed that stronger and prolonged fluorescent intensity observed after the administration of TfRMAb-conjugated nanospheres originated from the nanospheres translocated to the parenchyma by showing the Nile red accumulation in brain tissue with chemical detection as well as the presence of nanospheres in the parenchyma outside the vascular lumen with immunohistochemistry. For the latter two techniques, we had the opportunity to flush the vascular content with saline before sacrificing the animals therefore we ensured that the source of fluorescence observed was not in the vascular compartment. With chemical analysis of Nile red in the liver and spleen, we also verified that nanospheres are selectively transported to the brain possibly because the R17217 antibody we used has a higher affinity to the type $1 \mathrm{TfR}$ on the brain vasculature compared with the TfRs in other tissues (Lee et al., 2000).

We administered two doses of the peptide selected on the basis of estimates from in vitro release kinetics of the Z-DEVD-FMK from nanospheres and from the previously published efficient Z-DEVD-FMK doses used intracerebroventricularly in mouse studies (Ma et al., 1998, 2001). Nanospheres loaded with a higher concentration $(188 \mathrm{ng} / \mathrm{mg}$ ) of the peptide provided a robust reduction in infarct volume paralleled with a decrease in neurological deficits and caspase- 3 activity. Nanospheres provided neuroprotection even when given $2 \mathrm{~h}$ after ischemia in line with studies in which Z-DEVD-FMK was administered intracerebroventricularly (Ma et al., 1998, 2001). Although nanospheres loaded with a lower concentration ( $50 \mathrm{ng} / \mathrm{mg}$ ) of the peptide did not display significant peptide release in vitro, they should still be able to discharge at least a part of their peptide content in the brain tissue, as suggested by the considerable decrease observed in infarct volume and neurological deficit score. A small amount of released Z-DEVD-FMK may be diluted to undetectable concentrations in the test tube in vitro, whereas it might achieve considerable concentration in the minute interstitial volume of the brain. Additionally, the interstitial microenvironment may provide favorable conditions to facilitate release and degradation of chitosan but this issue remains to be investigated.

Published studies on mice have documented that therapeutic efficacy of caspase inhibitors is limited to the first hour after reperfusion following $2 \mathrm{~h}$ of MCA occlusion (Ma et al., 1998, 2001). Accordingly, we believe that nanospheres that are rapidly transferred across the BBB as shown by the intravital microscopy experiments, released sufficient amounts of Z-DEVD-FMK within a few hours to inhibit caspase- 3 activity in the ischemic tissue before the therapeutic window of $3 \mathrm{~h}$ is closed. In fact, we found an important inhibition of caspase- 3 enzymatic activity $1 \mathrm{~h}$ after reperfusion (that is, $3 \mathrm{~h}$ after injection) in the preischemia, high-dose nanosphere treatment group. In contrast, there was still robust caspase- 3 activity observed in the brain of mice administered with either the blank nanospheres or with the Z-DEVD-loaded nanospheres lacking the TfRMAb.

As shown previously, significant opening of the BBB starts only $6 \mathrm{~h}$ after ischemia/reperfusion (Nagaraja et al., 2008; Strbian et al., 2008). Therefore, the rapid transfer of nanospheres to the brain cannot be attributed to the increased permeability of the $\mathrm{BBB}$. This is also demonstrated by the absence of any effect displayed by Z-DEVD-FMK-loaded nanospheres that are not functionalized with the TfRMAb antibody. To ensure that functionalized nanospheres could efficiently cross the $\mathrm{BBB}$ and release DEVD peptide, caspase- 3 activity induced by developmental cell death in the cerebellar tissue was used as another assessment system. Extensive cerebellar apoptosis is, indeed, prominent on postnatal days 5-25 of neonatal mice (Wood et al., 1993). The BBB becomes mature and impermeable after postnatal day 14 in mice (Hallmann et al., 1995), whereas the transferrin receptor is widely expressed starting from postnatal day 5 (Bartlett et al., 1991). In line with these data, we indeed observed considerable caspase-3 p20 (the active cleaved form of caspase-3) immunoreactivity in the cerebellum on postnatal day 17 when the BBB was found intact, as detected by exclusion of Evans blue from the parenchyma. Accordingly, postnatal day 17 was selected as the optimal time point to study the penetration of transferrin receptor-targeted nanospheres through the intact $\mathrm{BBB}$. The enzymatic assay data clearly indicated that Z-DEVD-FMK-loaded nanospheres were able to inhibit cerebellar caspase- 3 activity in these mice, thereby unequivocally demonstrating that they could efficiently penetrate the brain tissue in a short time and then release sufficient amounts of Z-DEVD-FMK (cerebella were removed 3 h after i.v. injection).

In conclusion, this study clearly demonstrates that TfRMAbconjugated chitosan nanospheres are an efficient delivery system for bringing active peptides to the brain. This opens exciting prospects for the treatment of CNS disorders in which the use of medications is hampered by insufficient diffusion through the blood-brain barrier.

\section{References}

Aktaş Y, Yemisci M, Andrieux K, Gürsoy RN, Alonso MJ, Fernandez-Megia E, Novoa-Carballal R, Quiñoá E, Riguera R, Sargon MF, Celik HH, Demir 
AS, Hincal AA, Dalkara T, Capan Y, Couvreur P (2005) Development and brain delivery of chitosan-PEG nanoparticles functionalized with the monoclonal antibody OX26. Bioconjug Chem 16:1503-1511.

Asahi M, Hoshimaru M, Uemura Y, Tokime T, Kojima M, Ohtsuka T, Matsuura N, Aoki T, Shibahara K, Kikuchi H (1997) Expression of interleukin- 1 beta converting enzyme gene family and bcl-2 gene family in the rat brain following permanent occlusion of the middle cerebral artery. J Cereb Blood Flow Metab 17:11-18.

Bartlett WP, Li XS, Connor JR (1991) Expression of transferrin mRNA in the CNS of normal and jimpy mice. J Neurochem 57:318-322.

Braun JS, Prass K, Dirnagl U, Meisel A, Meisel C (2007) Protection from brain damage and bacterial infection in murine stroke by the novel caspase-inhibitor Q-VD-OPH. Exp Neurol 206:183-191.

Callus BA, Vaux DL (2007) Caspase inhibitors: viral, cellular and chemical. Cell Death Differ 14:73-78.

Calvo P, Remuñan-López C, Vila-Jato JL, Alonso MJ (1997) Chitosan and chitosan/ethylene oxide-propylene oxide block copolymer nanoparticles as novel carriers for proteins and vaccines. Pharm Res 14:1431-1436.

Chen J, Nagayama T, Jin K, Stetler RA, Zhu RL, Graham SH, Simon RP (1998) Induction of caspase-3-like protease may mediate delayed neuronal death in the hippocampus after transient cerebral ischemia. J Neurosci 18:4914-4928.

Fernandez-Megia E, Novoa-Carballal R, Quiñoá E, Riguera R (2005) Optimal routine conditions for the determination of the degree of acetylation of chitosan by 1H-NMR. Carbohydr Polym 61:155-161.

Fernandez-Megia E, Novoa-Carballal R, Quiñoá E, Riguera R (2007) Conjugation of bioactive ligands to PEG-grafted chitosan at the distal end of PEG. Biomacromolecules 8:833-842.

Gessner A, Olbrich C, Schröder W, Kayser O, Müller RH (2001) The role of plasma proteins in brain targeting: species dependent protein adsorption patterns on brain-specific lipid drug conjugate (LDC) nanoparticles. Int J Pharm 214:87-91.

Green RA, Odergren T, Ashwood T (2003) Animal models of stroke: do they have value for discovering neuroprotective agents? Trends Pharmacol Sci 24:402-408.

Greenspan P, Mayer EP, Fowler SD (1985) Nile red: a selective fluorescent stain for intracellular lipid droplets. J Cell Biol 100:965-973.

Gürsoy-Ozdemir Y, Bolay H, Saribaş O, Dalkara T (2000) Role of endothelial nitric oxide generation and peroxynitrite formation in reperfusion injury after focal cerebral ischemia. Stroke 31:1974-1981.

Hallmann R, Mayer DN, Berg EL, Broermann R, Butcher EC (1995) Novel mouse endothelial cell surface marker is suppressed during differentiation of the blood brain barrier. Dev Dyn 202:325-332.

Hara H, Friedlander RM, Gagliardini V, Ayata C, Fink K, Huang Z, ShimizuSasamata M, Yuan J, Moskowitz MA (1997) Inhibition of interleukin lbeta converting enzyme family proteases reduces ischemic and excitotoxic neuronal damage. Proc Natl Acad Sci U S A 94:2007-2012.

Huang Z, Huang PL, Panahian N, Dalkara T, Fishman MC, Moskowitz MA (1994) Effects of cerebral ischemia in mice deficient in neuronal nitric oxide synthase. Science 265:1883-1885.

Jefferies WA, Brandon MR, Hunt SV, Williams AF, Gatter KC, Mason DY (1984) Transferrin receptor on endothelium of brain capillaries. Nature 312:162-163.
Kidwell CS, Liebeskind DS, Starkman S, Saver JL (2001) Trends in acute ischemic stroke trials through the 20th century. Stroke 32:1349-1359.

Lamarque G, Lucas JM, Viton C, Domard A (2005) Physicochemical behavior of homogeneous series of acetylated chitosans in aqueous solution: role of various structural parameters. Biomacromolecules 6:131-142.

Lee HJ, Engelhardt B, Lesley J, Bickel U, Pardridge WM (2000) Targeting rat anti-mouse transferrin receptor monoclonal antibodies through bloodbrain barrier in mouse. J Pharmacol Exp Ther 292:1048-1052.

Ma J, Endres M, Moskowitz MA (1998) Synergistic effects of caspase inhibitors and MK-801 in brain injury after transient focal cerebral ischaemia in mice. Br J Pharmacol 124:756-762.

Ma J, Qiu J, Hirt L, Dalkara T, Moskowitz MA (2001) Synergistic protective effect of caspase inhibitors and bFGF against brain injury induced by transient focal ischaemia. Br J Pharmacol 133:345-350.

Nagaraja TN, Keenan KA, Fenstermacher JD, Knight RA (2008) Acute leakage patterns of fluorescent plasma flow markers after transient focal cerebral ischemia suggest large openings in blood-brain barrier. Microcirculation 15:1-14.

Namura S, Zhu J, Fink K, Endres M, Srinivasan A, Tomaselli KJ, Yuan J, Moskowitz MA (1998) Activation and cleavage of caspase-3 in apoptosis induced by experimental cerebral ischemia. J Neurosci 18:3659-3668.

Pardridge WM, Buciak JL, Friden PM (1991) Selective transport of an antitransferrin receptor antibody through the blood-brain barrier in vivo. J Pharmacol Exp Ther 259:66-70.

Renolleau S, Fau S, Goyenvalle C, Joly LM, Chauvier D, Jacotot E, Mariani J, Charriaut-Marlangue C (2007) Specific caspase inhibitor Q-VD-OPh prevents neonatal stroke in P7 rat: a role for gender. J Neurochem 100:1062-1071.

Royer GP, Anantharmaiah GM (1979) Peptide synthesis in water and the use of immobilized carboxypeptidase Y for deprotection. J Am Chem Soc 101:3394-3396.

Schielke GP, Yang GY, Shivers BD, Betz AL (1998) Reduced ischemic brain injury in interleukin-1 beta converting enzyme-deficient mice. J Cereb Blood Flow Metab 18:180-185.

Schulz JB, Weller M, Moskowitz MA (1999) Caspases as treatment targets in stroke and neurodegenerative diseases. Ann Neurol 45:421-429.

Strbian D, Durukan A, Pitkonen M, Marinkovic I, Tatlisumak E, Pedrono E, Abo-Ramadan U, Tatlisumak T (2008) The blood-brain barrier is continuously open for several weeks following transient focal cerebral ischemia. Neuroscience 153:175-181.

Swanson RA, Morton MT, Tsao-Wu G, Savalos RA, Davidson C, Sharp FR (1990) A semiautomated method for measuring brain infarct volume. J Cereb Blood Flow Metab 10:290-293.

Thornberry NA, Lazebnik Y (1998) Caspases: enemies within. Science 281:1312-1316.

Wood KA, Dipasquale B, Youle RJ (1993) In situ labeling of granule cells for apoptosis-associated DNA fragmentation reveals different mechanisms of cell loss in developing cerebellum. Neuron 11:621-632.

Yoshikawa T, Pardridge WM (1992) Biotin delivery to brain with a covalent conjugate of avidin and a monoclonal antibody to the transferrin receptor. J Pharmacol Exp Ther 263:897-903.

Zhang J, Xu M (2002) Apoptotic DNA fragmentation and tissue homeostasis. Trends Cell Biol 12:84-89. 